\title{
Cigarette smoking induces overexpression of c-Met receptor in microvessels of oral lichen planus
}

\author{
Sebastian K. Kłosek ${ }^{1}$, Stanisław Sporny ${ }^{2}$, Olga Stasikowska-Kanicka ${ }^{3}$, Anna J. Kurnatowska ${ }^{1}$
}

1Department of Periodontology and Oral Mucosal Diseases, Medical University of Lodz, Poland

2Department of Oral Pathology, Medical University of Lodz, Poland

3Department of Nephropathology, Medical University of Lodz, Poland

Submitted: 4 April 2010

Accepted: 13 June 2010

Arch Med Sci 2011; 7, 4: 706-712

DOI: $10.5114 /$ aoms.2011.24143

Copyright @ 2011 Termedia \& Banach

\section{Abstract}

Introduction: Cigarette smoking is related to many pathological conditions; however, chemical substances affect the oral cavity first, so it is important to consider its influence on oral mucosa and oral potentially pre-malignant lesions. The aim of this study was to investigate the effect of smoking on microvessel density in oral lichen planus. Special emphasis was placed on examining the relationship between the expression of c-Met receptor in blood vessels and smoking habits.

Material and methods: This study included 34 patients with oral lichen planus diagnosed clinically and verified by histopathological examination and 12 healthy individuals as controls. Biopsy of oral mucosa was performed and specimens were examined for immunohistochemical CD34 and c-Met receptor expression. The microvessel density was established by evaluation of the five most vascular areas within a section.

Results: Compared to normal oral mucosa, in lichen planus patients, significantly higher blood vessel density and c-Met expression were noted. Irregular distribution of microvessels was typical for oral lichen planus. Also, microvessel density was higher in cigarette smoking patients' tissues than in non-smoker specimens. Furthermore, the association of c-Met expression with smoking habit was statistically significant.

Conclusions: Cigarette smoking habit has a direct impact on the oral lichen planus course; therefore, close follow-up of these patients is mandatory.

Key words: oral lichen planus, cigarette smoking, c-Met, microvessel density.

\section{Introduction}

Cigarette smoking is the most established risk factor for lung carcinogenesis, and lung cancer is the leading cause of cancer mortality worldwide [1, 2]. An association with other malignancies (i.e., cancer of head and neck, pancreas, liver, uterine cervix, oesophagus, stomach and kidney) has also been shown $[3,4]$. Cigarette smokers are at 2 to 5 times higher risk of oral cancer than non-smokers, and the risk increases with the number of cigarettes and years smoked [5]. Oral cancer cases and deaths are due to both individual predisposition, linked to specific genetic characteristics, and exposure to carcinogens, among which $20-30 \%$ of overall cases are attributable to tobacco smoking [6-8]. Nevertheless, smokeless tobacco (betel-quid) may also lead to malignant transformation

\author{
Corresponding author: \\ Sebastian K. Kłosek MD, PhD \\ Department of \\ Periodontology \\ and Oral Mucosal Diseases \\ Medical University of Lodz \\ 251 Pomorska \\ 92-216 Lodz, Poland \\ Phone/fax: +48 426757540 \\ E-mail: ganbaro@gmail.com
}


- $50 \%$ of men and almost $90 \%$ of women presenting this habit $[8,9]$.

Smoking is also associated with potentially malignant disorders of the oral and oropharyngeal mucosa, especially with leukoplakia and erythroplakia [10, 11], with risk increasing in a dosedependent manner and declining with the duration of smoking cessation [12]. However, little is known about the influence of cigarette smoke content on the course of oral lichen planus (OLP) and its potential of malignant transformation [13]. Some researchers speculate that the development of cancer in OLP could result from an interaction of the atrophic mucosa with tobacco carcinogens [14]. Betel-quid lichenoid lesion has been described as a reaction to chewing tobacco, but a causal role for betel has not been clearly established [15]. Moreover, tobacco could support tissue destruction in OLP through irritation and other well-established mechanisms, such as functional alterations in chemotaxis and phagocytosis of neutrophils, elevating levels of TNF, PGE 2 , neutrophil elastase and MMPs, as well as vasoconstrictory effect with lower oxygen concentration in tissue [16-19].

In this study, we investigated cigarette smoking effects on microvessels of OLP. Special concern was given to the expression of c-Met receptor, which has been shown to be overexpressed in human malignancies and to promote cancer cell growth $[20,21]$.

\section{Material and methods}

\section{Patients}

This study included 34 patients ( 24 women and 10 men) referred for the first time to the Department of Periodontology and Oral Mucosal Diseases of the Medical University of Lodz during the period of 2007-2009, with clinically diagnosed oral lichen planus. Clinical diagnosis of lichen planus was confirmed by iodide test. The mean age of examined patients was $61.5 \pm 8.2$ years for women (range: 52 to 68 years), and $64 \pm 5.8$ years for men (range: 58 to 69 years). The duration of the disease prior to presentation ranged from 3 weeks to 3 years. Healthy individuals [12] undergoing periodontal procedures were enrolled as controls. All the patients considered as cigarette smokers smoked about 10-20 cigarettes a day, and have been smoking for longer than 20 years. Non-smokers have never smoked at all; therefore in our group there were no ex-smokers.

The research has been conducted in full accordance with ethical principles including the World Medical Association Declaration of Helsinki (ver. 2002). The study has been reviewed and approved by the ethical board of the Medical University of Lodz.

\section{Biopsy}

The biopsy from the lichen planus lesions was fixed in $10 \%$ formalin and then routinely processed for paraffin embedding and haematoxylin and eosin $(H \& E)$ staining to confirm the clinical diagnosis of OLP.

\section{Immunohistochemistry}

Tissue samples were fixed in $10 \%$ buffered formalin and embedded in paraffin. Tissue sections were cut $(4 \mu \mathrm{m})$, deparaffinized with xylene, and rehydrated through graduated ethanol solutions. The slides were treated with target retrieval solution (Dako, Carpenteria, CA) at $97^{\circ} \mathrm{C}$ for $45 \mathrm{~min}$. Further, the sections were treated with $3 \%$ hydrogen peroxide in methanol for $30 \mathrm{~min}$ to quench endogenous peroxidase activity. Nonspecific reactions were then blocked with $5 \%$ dried milk in phosphate-buffered saline (PBS) for $1 \mathrm{~h}$ at room temperature and the sections incubated overnight at $4^{\circ} \mathrm{C}$ with rabbit anti-human c-Met polyclonal antibody (1: 50; Santa Cruz Biotechnology, Santa Cruz, CA), and mouse anti-human CD34 monoclonal antibody (1 : 50; DakoCytomation Denmark A/S). Multi-use secondary antibody (EnVision System; Dako) was applied to the tissues for $1 \mathrm{~h}$ at room temperature. Peroxidase activity was visualized with a 3,3'diaminobenzidine tetrahydrochloride solution containing $0.05 \%$ hydrogen peroxidase (DAB Liquid System; Dako) and the sections were counterstained with haematoxylin for $3 \mathrm{~min}$, dehydrated through graduated ethanol solutions, cleared with xylene, and mounted. Staining intensity was evaluated by systematically screening all slices and evaluating them according to an established 0-3 scale. The immunohistochemical results for c-Met protein were classified as follows: 0 - no staining, 1 - weak, 2 - moderate, 3 - strong. The membrane staining and cytoplasmic staining were evaluated. Samples graded as 0 and 1 were considered negative, 2 and 3 as positive.

\section{Microvessel density}

Immunohistochemical staining for CD34 to highlight the endothelial cells was performed. For the determination of microvessel density (MVD), the total microvessels number per chosen area was evaluated. The five most vascular areas within a section were selected and counted under a light microscope with 200-fold magnification (i.e., 20x objective lens and 10x ocular lens; $0.7386 \mathrm{~mm}^{2} /$ field) as described by Weindner et al. [22]. Each area was counted twice and the arithmetical mean of values was used to calculate the mean for a section. 


\section{Statistical analysis}

The correlation between c-Met receptor expression and cigarette smoking, as well as the expression of the protein and clinicopathological parameters were evaluated using Fisher's exact test.
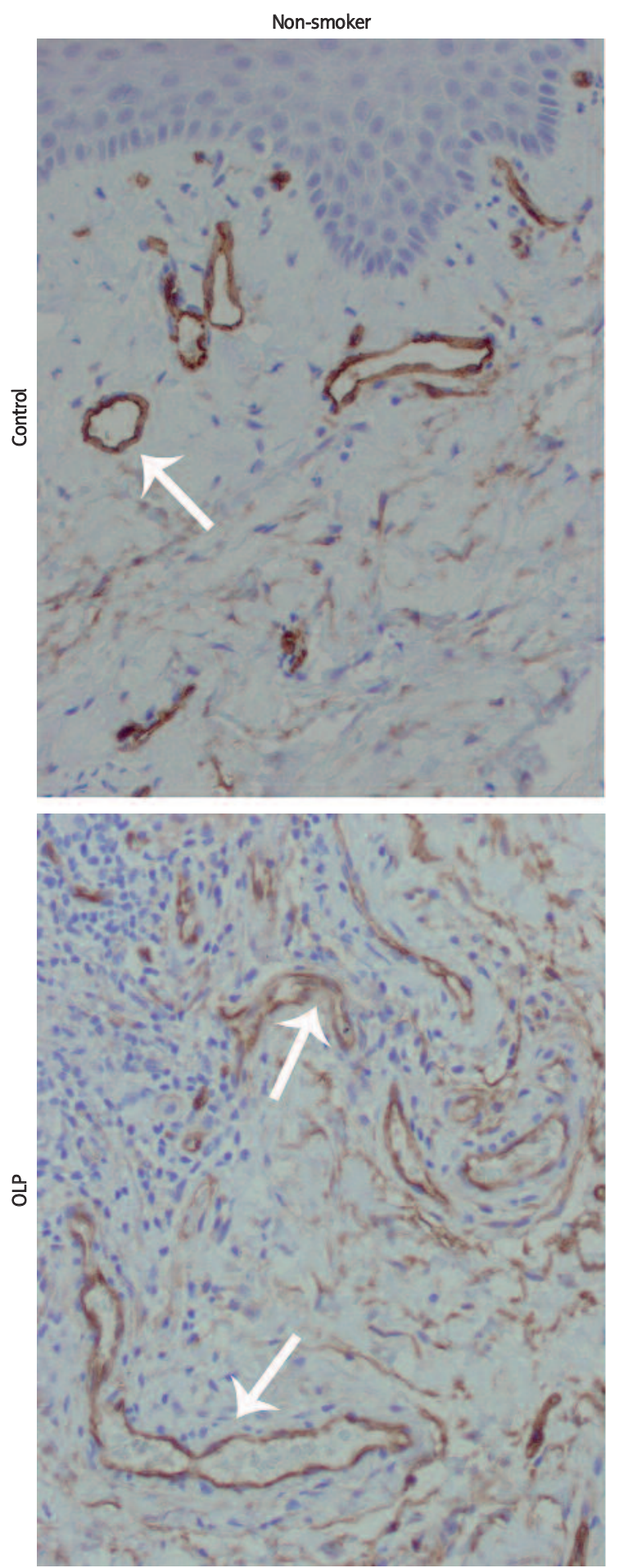

Pearson's correlation coefficient analysis was performed to determine the overall correlation between MVD and smoking habit and c-Met expression. All $p$-values $<0.05$ were considered statistically significant.
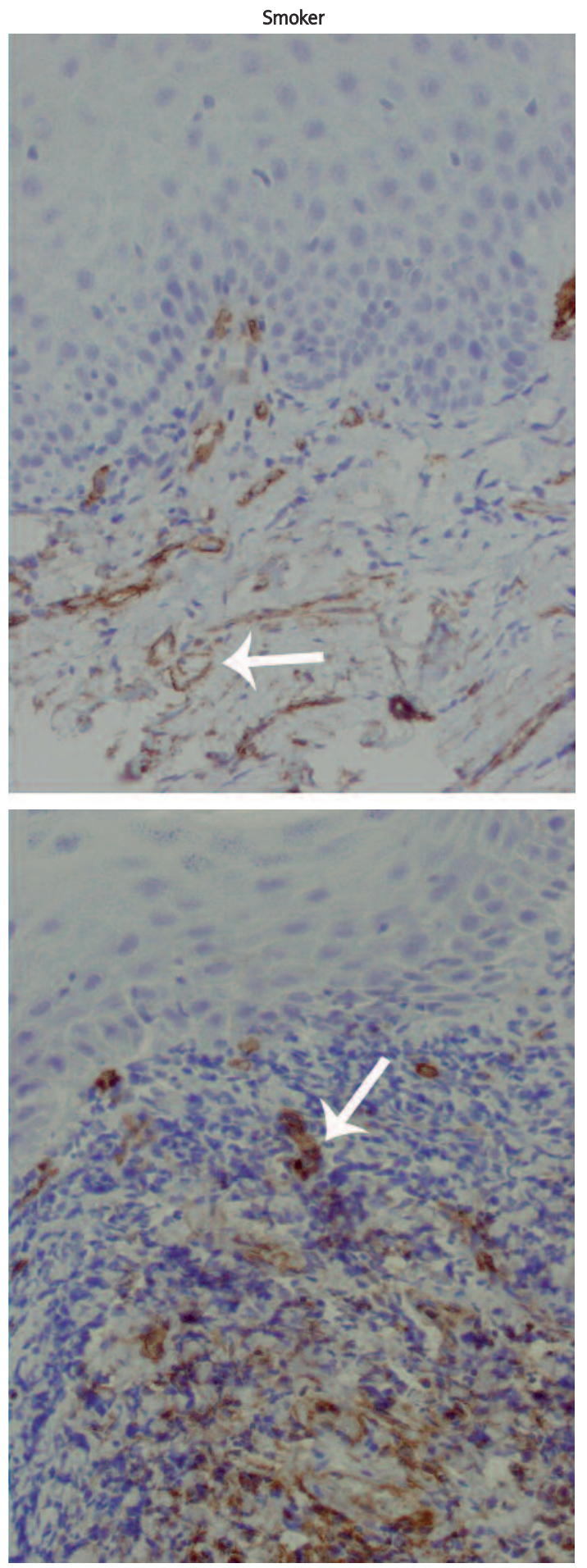

Figure 1. Blood vessels pattern by CD34 staining in control and OLP tissues. Blood vessels distributed regularly in control samples of non-smokers, with regular cross-sections, but with smaller diameter in smoking control samples (upper pictures). Elongated vessels irregularly distributed in OLP non-smokers; in OLP smokers numerous smalldiameter cross-sections of vessels (lower pictures). All presented samples derived from women. Arrows mark blood vessels (mag. 200x) 


\section{Results}

Clinical examination of all patients revealed papules and plaques with some irregular reticular aspects and the erythematous background. Intraorally, the most affected anatomical site was the buccal mucosa (67\%), followed by tongue (20\%), alveolar mucosa (10\%), and palate (3\%). Painful and burning symptoms were reported in all cases.

Histopathological analysis confirmed the clinical diagnosis of OLP in all cases. All specimens showed infiltration of inflammatory cells with a predominance of lymphocytes forming a dense band under the epithelium. Features of hydropic degeneration of the basal cell layer with local loss of distinct epithelial-connective tissue interface were observed. Hyperkeratosis was noted. Further, irregular acanthotic hyperplasia in $50 \%$ of the cases was found. No epithelial dysplasia was present.

In this study, we concentrated on the microvessel aspect of OLP. In normal tissues and OLP specimens, microvessels were mainly located immediately underneath the epithelium. In control tissues of non-smokers, microvessels were regularly distributed and had rather regular cross-sectional shapes. In OLP tissues of non-smokers, the vessels were irregularly distributed and had usually elongated cross-sections, and vessels with very small diameter were numerous. However, in cigarette smoking patients of both groups, the diameter of vessel cross-sections was smaller in comparison to non-smoking patients (Figure 1). The accumulation of small-diameter microvessels in OLP specimens of smokers was markedly higher than in OLP tissues of non-smokers. Within each of the investigated groups, differences in microvessels morphology or density between specimens derived from men or women were not observed.

Generally, in non-smoking groups, the microvessel density (MVD; mean \pm SD) was $24.8 \pm 4.4$ in control, and $37.6 \pm 6.1$ in OLP tissues. Nevertheless, MVD was higher in cigarette smoking patients' tissues than in non-smoker specimens (Figure 2), and in both examined groups statistically correlated with cigarette smoking habit $(p<0.05)$. Cigarette smokers with OLP showed MVD at the level of 52.8 \pm 8.6 , but non-smokers with OLP presented MVD at the level of $37.6 \pm 6.1$, which indicated the statistical correlation between smoking habit and MVD increase in the OLP group $(p<0.05)$.

Table I. Correlation between the expression of c-Met and smoking habit in OLP patients

\begin{tabular}{|lcc|}
\hline Habit & \multicolumn{2}{c|}{ c-Met } \\
\cline { 2 - 3 } & Negative & Positive \\
\hline Non-smokers & $10(29.4 \%)$ & $6(17.6 \%)$ \\
\hline Smokers & 0 & $18(53 \%)$ \\
\hline Correlation, $p<10^{-6}$ & &
\end{tabular}

Figure 2. Comparison of MVD between control and OLP patients with regard to smoking habit. The MVD was markedly higher in cigarette smoking groups of control and OLP. Mean values and standard deviation are presented

Immunohistochemical staining for c-Met is presented in Figure 3. Of all OLP samples, 70.6\% were positive for membrane and cytoplasmic c-Met staining in endothelial cells; among them, 6 samples of non-smokers and 18 samples of cigarette smokers (Table I). The association of c-Met expression with smoking habit was statistically significant within the OLP group $\left(p<10^{-6}\right)$. In the group of healthy individuals, $50 \%$ of samples were positive for c-Met endothelial staining, and among them, $41.64 \%$ (5 samples) were obtained from cigarette smokers. Fisher's exact test correlation for $c-$ Met expression and smoking habit was statistically significant ( $p=0.039$, Table II).

Furthermore, mean MVD was $54.0 \pm 9.3$ in c-Met positive OLP samples and $40.2 \pm 6.2$ in c-Met negative OLP samples. Therefore, it was higher in samples expressing c-Met. Pearson's correlation was significant in OLP patients $(p<0.05)$. Seventyfive percent of c-Met positive patients smoked tobacco. Within the c-Met positive group, OLP smokers showed MVD at the level of $55.1 \pm 2.6$ and OLP non-smokers at the level of $49.3 \pm 5.3$, and the difference was statistically significant $(p<0.05)$.

\section{Discussion}

To evaluate the role of angiogenesis in OLP lesions with special concern for the influence of tobacco

Table II. Correlation between the expression of c-Met and smoking habit in healthy patients

\begin{tabular}{|lcc|}
\hline Habit & \multicolumn{2}{c|}{ c-Met } \\
\cline { 2 - 3 } & Negative & Positive \\
\hline Non-smokers & $5(41.66 \%)$ & $1(8.34 \%)$ \\
\hline Smokers & $1(8.34 \%)$ & $5(41.66 \%)$ \\
\hline
\end{tabular}



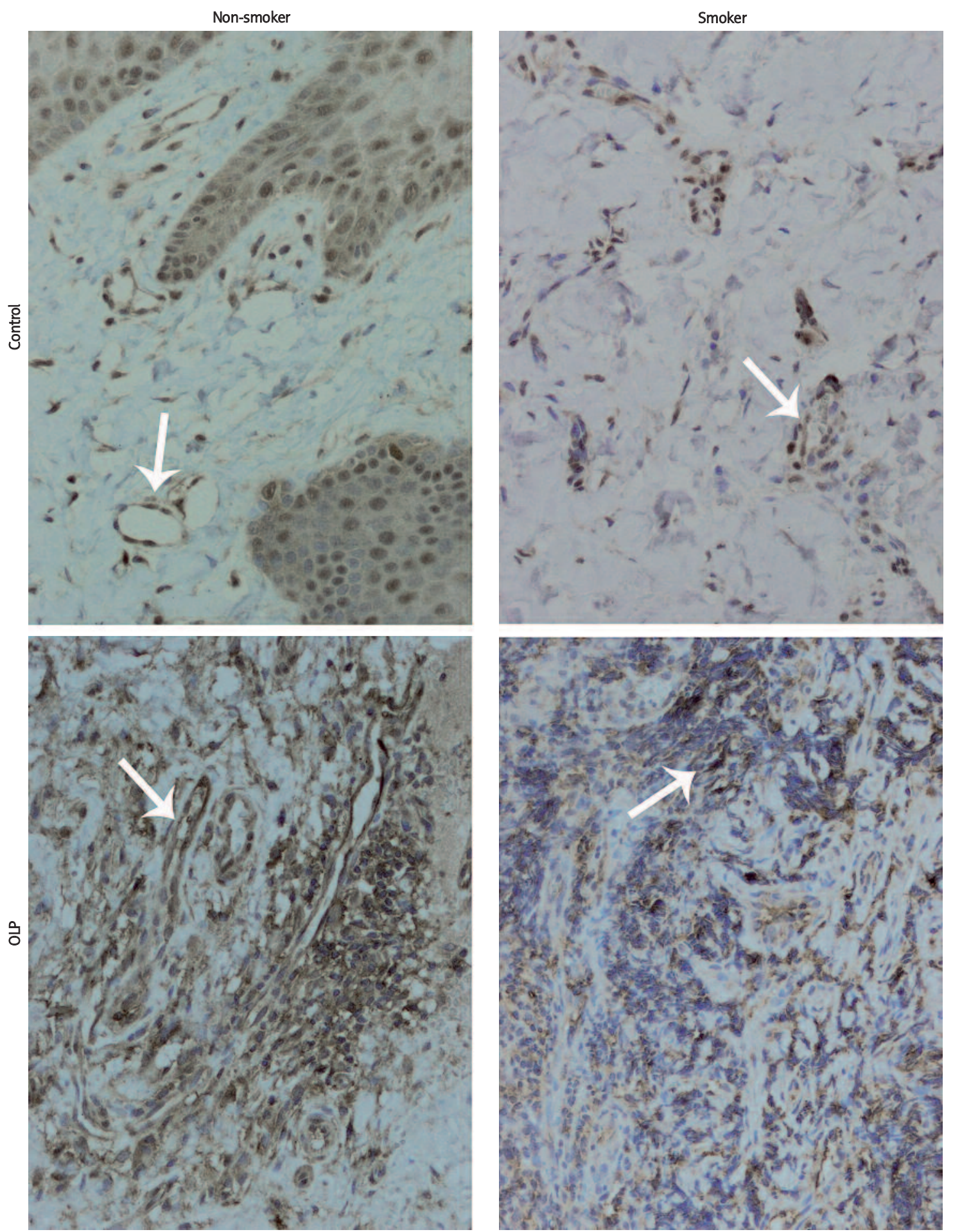

Figure 3. C-Met staining in control and OLP tissues. Increased staining of c-Met receptor in endothelial cells of OLP groups was noted. Smaller cross-sections of vessels in OLP smokers were characteristic. All presented samples derived from women. Arrows mark blood vessels (mag. 200x)

smoke on vascularization, we analysed MVD in healthy and diseased individuals with or without smoking habits, and compared the MVD between patients with OLP diagnosed with or without such addiction. First, we considered MVD in normal and OLP specimens, and we found a significant difference between these two groups. The MVD in the OLP group was higher in comparison to the control group; however, some previous studies have shown no significant difference between normal mucosa and pre-malignant lesions [23]. Li et al. have also shown no significant correlation; however, in their study, MVD increase was parallel to tumour volume during its growth [24]. In the present study, the higher MVD 
in OLP specimens might be the result of inflammation and the increase in blood vessels due to proinflammatory cytokine action since all patients showed an erythematous background of OLP lesions, which indicates that local microvasculature may undergo an intense process of inflammationdependent angiogenesis [17]. Similarly, dermal MVD was also increased in cutaneous lichen planus as checked by CD34 staining [25]. Further, by videocapillaroscopy, an increase in capillary diameter and density in lichen planus of gingiva compared to the control patients has been reported [26]. Moreover, Lopez de Blanc et al. showed that lesions of lichen planus are more congestive than leukoplakia [27].

Next, we observed increased MVD in patients of OLP with smoking habit in comparison to those of OLP non-smokers. The MVD was by almost onethird higher when OLP patients smoked. The increased MVD in samples obtained from smoking patients might be the result of compensatory angiogenesis due to lower oxygen concentration in tissue, and the smaller diameter of blood vessels was the effect of vasoconstriction evoked by tobacco smoke. Interestingly, there are no other reports showing such correlation.

Further, we analysed the expression of c-Met in endothelial cells. c-Met protein is a receptor for hepatocyte growth factor (HGF), which was originally identified as a potent mitogen that stimulates the growth of hepatocytes, as well as the proliferation, migration, survival, angiogenesis and invasion in human malignancies [28]. Moreover, c-Met is known as an oncogene and its overexpression has been reported in many human tumours [29]. Previously, we have shown that c-Met together with CD151 tetraspanin controls the signal passage for proliferation in human salivary gland cells [21], and that the mentioned protein complex is important in human breast cancer cells, MDAMB-231, for cord-like structure formation, which imitate the morphogenesis or angiogenesis in vivo [30]. Interestingly, since c-Met and its ligand play a role in blood vessel formation, inhibition of the HGF/c-Met signalling pathway has been shown to stop angiogenesis in multiple in vitro and in vivo models [31]. Therefore c-Met is recognized as a promising target in cancer therapy.

In our study, all control and OLP samples showed expression of c-Met in endothelial cells. However, in some cases the expression was weak, which could not be considered positive staining. Nevertheless, $70.6 \%$ of OLP were positive for c-Met staining and the data directly correlated with smoking habit. Moreover, we showed increased values of MVD in OLP smokers in comparison to non-smokers. Of all c-Met positive samples, $75 \%$ were derived from smokers. Previously, the expression of c-Met on endothelial cells has been reported, and omnipresence of this receptor was frequently accompanied by increased HGF concentration in many pathological conditions [32]. Furthermore, it has been reported that nicotine upregulated HGF expression in lung cancer tissues, as well as in type II normal pneumocytes with overexpression of c-Met frequently detected in adenocarcinoma cells [33]. Thus smoking might play a key role in promoting disease progression via activation of the HGF/c-Met pathway.

This all is convergent with our study, where smoking habit correlated with both MVD and c-Met positive staining. The results support the role of cigarette smoking in the progression of microvascular changes in OLP tissues. Therefore, in the light of previous reports and our conclusions, it is of high importance to advise patients with OLP cigarette smoking cessation, and follow them closely in order not to overlook any signs of malignant transformation.

\section{Acknowledgments}

This study was supported by the grant for scientific research No. 502-12-613, from the Medical University of Lodz, as well as by a grant for scientific research in 2007-2010, from the Ministry of Science and Higher Education of Poland (NN401097833 to SKK).

\section{References}

1. Winn DM. Tobacco use and oral disease. J Dent Educ 2001; 65: 306-12.

2. Van der Vaart H, Postma DS, Timens W, Hacken NH. Acute effects of cigarette smoke on inflammation and oxidative stress: a review. Thorax 2004; 59: 713-21.

3. Mena S, Ortega A, Estrela JM. Oxidative stress in environmental-induced carcinogenesis. Mutat Res 2009; 674: 36-44.

4. Dautzenberg B. Tobacco-related diseases. Rev Prat 2004; 54: $1877-82$.

5. Wald NJ, Hackshaw AK. Cigarette smoking: an epidemiological overview. Br Med Bull 1996; 52: 3-11.

6. Valko M, Leibfritz D, Moncol J, Cronin MT, Mazur M, Telser J. Free radicals and antioxidants in normal physiological functions and human disease. Int J Biochem Cell Biol 2007; 39: 44-84.

7. Hecht SS. Tobacco carcinogens, their biomarkers and tobacco-induced cancer. Nat Rev Cancer 2003; 3: 733-44.

8. Hashibe M, Brennan P, Benhamous S, et al. Alcohol drinking in never users of tobacco, cigarette smoking in never drinkers, and the risk of head and neck cancer: pooled analysis in the international head and neck cancer epidemiology consortium. J Natl Cancer Inst 2007; 99: 777-89.

9. Nair U, Bartsch H, Nair J. Alert for an epidemic of oral cancer due to use of the betel quid substitutes gutkha and pan masala: a review of agents and causative mechanisms. Mutagenesis 2004; 19: 251-62.

10. Dietrich T, Reichart PA, Scheifele C. Clinical risk factors of oral leukoplakia in a representative sample of the US population. Oral Oncol 2004; 40: 158-63. 
11. Banoczy J, Gintner Z, Dombi C. Tobacco use and oral leukoplakia. J Dent Educ 2001; 65: 322-7.

12. Morse DE, Psoter WJ, Cleveland D, et al. Smoking and drinking in relation to oral cancer and oral epithelial dysplasia. Cancer Causes Contr 2007; 18: 919-29.

13. Gandolfo S, Richiardi L, Carrozo M, et al. Risk of squamous cell carcinoma in 402 patients with oral lichen planus: a follow-up in an Italian population. Oral Oncol 2004; 40: 77-83.

14. Gonzales-Moles MA, Scully C, Gil-Montoya JA. Oral lichen planus: controversies surrounding malignant transformation. Oral Dis 2008; 14: 229-43.

15. Ismail SB, Kumar SK, Zain RB. Oral lichen planus and lichenoid reactions: etiopathogenesis, diagnosis, management and malignant transformation. J Oral Sci 2007; 49: 89-106.

16. Newman MG, Takei HH, Klokkevold PR, Carranza FA Carranza's clinical periodontology. $10^{\text {th }}$ ed. Saunders Elsevier: Missouri 2007; 254-5.

17. Regezi JA, Sciubba JJ, Jordan RCK. Oral pathology. Clinical Pathologic Correlations. $5^{\text {th }}$ ed. Saunders Elsevier: Missouri 2008; 90-5.

18. La Rocca G, Anzalone R, Magno F, et al. Cigarette smoke exposure inhibits extra cellular MMP-2 (gelatinases) activity in human lung fibroblasts. Respir Res 2007; 8: 1186-465.

19. Kaddah S, Rashed L, Obaia E, Sabry D. A preliminary study: matrix metalloproteinase expression as an indicator of the hazards of shisha (nargila) smoking. Arch Med Sci 2009; 5: 570-6.

20. Klosek SK, Nakashiro KI, Hara S, Li C, Shintani S, Hamakawa $\mathrm{H}$. Constitutive activation of Stat3 correlates with increased expression of the c-Met/HGF receptor in oral squamous cell carcinoma. Oncol Rep 2004; 12: 293-6.

21. Klosek SK, Nakashiro K, Hara S, Shintani S, Hasegawa H, Hamakawa H. CD151 forms a functional complex with c-Met in human salivary gland cancer cells. Biochem Biophys Res Commun 2005; 336: 408-16.

22. Weidner N, Carroll PR, Flax J, Blumenfeld W, Folkman J. Tumor angiogenesis correlates with metastasis in invasive prostate carcinoma. Am J Pathol 1993; 143: 401-9.

23. Tae K, El-Naggar AK, Yoo E, et al. Expression of vascular endothelial growth factor and microvessel density in head and neck tumorigenesis. Clin Cancer Res 2000; 6: 2821-8.

24. Li C, Shintani S, Terakado N, et al. Microvessel density and expression of vascular endothelial growth factor, basic fibroblast growth factor, and platelet-derived endothelial growth factor in oral squamous cell carcinomas. Int J Oral Maxillofac Surg 2005; 34: 559-65.

25. Hussein MR. Evaluation of angiogenesis in normal and lichen planus skin by CD34 protein immunohistochemistry: preliminary findings. Cell Biol Int 2007; 31: 1292-5.

26. Scardina GA, Cacioppo A, Carini F, Ruggieri A, Valenza V, Messina P. Periodontal morphological microcirculation in oral lichen planus. Ital J Anat Embriol 2007; 112: 281-91.

27. Lopez de Blanc S, Gendelman H, Itoiz ME, Lanfranchi H. Study of the vascular pattern in oral lichen planus. Acta Odontol Latinoam 1996; 9: 27-36.

28. Nakashiro K, Hara S, Shinohara Y, et al. Phenotypic switch from paracrine to autocrine role of hepatocyte growth factor in an androgen-independent human prostatic carcinoma cell line, CWR22R. Am J Pathol 2004; 165: 533-40.
29. Ma PC, Tretiakova MS, Mackinnon AC, et al. Expression and mutational analysis of MET in human solid cancers. Genes Chrom Cancer 2008; 47: 1025-37.

30. Klosek SK, Nakashiro K, Hara S, Goda H, Hasegawa H, Hamakawa H. CD151 regulates HGF-stimulated morphogenesis of human breast cancer cells. Biochem Biophys Res Commun 2009; 379: 1097-100.

31. You WK, McDonald DM. The hepatocyte growth factor/ c-Met signaling pathway as a therapeutic target to inhibit angiogenesis. BMB Rep 2008; 41: 833-9.

32. Mori T, Shimizu A, Masuda Y, Fukuda Y, Yamanaka N. Hepatocyte growth factor - stimulating endothelial cell growth and accelerating glomerular capillary repair in experimental progressive glomerulonephritis. Nephron Exp Nephrol 2003; 94: 44-54.

33. Chen JT, Lin TS, Chow KC, et al. Cigarette smoking induces overexpression of hepatocyte growth factor in type II pneumocytes and lung cancer cells. Am J Respir Cell Mol Biol 2006; 34: 264-73. 